\title{
Simulations of alpha particle ripple loss from the International Thermonuclear Experimental Reactor
}

\author{
M. H. Redi, R. V. Budny, D. C. McCune, C. O. Millera, R. B. White
}

Princeton Plasma Physics Laboratory,

\author{
P. O. Box 451 , \\ Princeton, NJ 08543 \\ AECERES \\ mov 28 res \\ 03 II
}

Calculations of collisional stochastic ripple loss of alpha particles from the new 20 toroidal field (TF) coil International Thermonuclear Experimental Reactor (ITER) [Plasma Physics and Controlled Nuclear Fusion Research (International Atomic Energy Agency, Vienna, 1991), Vol. 3, p. 239] predict small alpha ripple losses, less than $0.4 \%$, close to the loss calculated for the full current operation of the earlier 24 TF coil design. An analytic fit is obtained to the ITER ripple data field demonstrating the nonlinear height dependence of the ripple minimum for $\mathrm{D}$ shaped ripple contours. In contrast to alpha loss simulations for the Tokamak Fusion Test Reactor (TFTR) [Fusion Technol. 21 (1992) 1324], a simple Goldston, White, Boozer stochastic loss criterion [Phys. Rev. Lett. 47 (1981) 647] ripple loss model is found to require an increased renormalization of the stochastic threshold $\delta_{S} / \delta G W B \geq 1$. Effects of collisions, sawtooth broadening and reversal of the grad $B$ drift direction are included in the particle following simulations.

PACS 52.55, 28.52, 52.65

aPresent address: Richard Stockton College of New Jersey, Pomona, NJ 08240 


\section{INTRODUCTION}

Design of the proposed International Thermonuclear Experimental Reactor (ITER) $1,2,3,4$ is the culmination of a major cooperative effort to develop fusion science for world energy resource planning. Recent modification of ITER ${ }^{3}$ to reduce the number of toroidal field (TF) coils from 24 to 20 would reduce costs, but has given rise to questions about alpha particle stochastic ripple loss damage to the first wall. In the last few years, the production of alpha particles on the Tokamk Fusion Test Reactor (TFTR) ${ }^{5}$ in deuterium-tritium (DT) experiments 6 has stimulated numerous new developments in theoretical, modelling and experimental investigations of fast particle ripple loss on tokamaks $7-18$. In this paper we summarize detailed calculations of alpha ripple loss in ITER finding ripple losses similar to previous predictions for full current operation of the 24 TF coil ITER. Details of the as yet uncompleted engineering design are needed to evaluate the first wall heat load.

Section II describes the simulation methods including development of an analytic fit to the TF ripple data field. Section III presents the results of guiding center code calculations, including a detailed analysis of collisions and sawtooth effects. In this section, comparison is made with a simple model ${ }^{12}$ for stochastic ripple loss based on the Goldston, White, Boozer (GWB) criterion ${ }^{19}$, which has been found useful for analysis of TFTR DT experiments ${ }^{13}$. A summary and concluding discussion is given in Section IV.

\section{ITER RIPPLE LOSS CALCULATIONS}

Magnetic confinement of thermonuclear plasma ions within a tokamak must be achieved with a finite number of toroidal field coils. This results in a "broken symmetry" 20 , a rippled toroidal field structure, and consequent distortions in fast ion orbits with potentially rapid loss of affected ions. This "ripple loss" of alphas can result in reduced alpha heating as well as potentially severe localized wall damage in fusion reactors. The possibility of such serious problems from alpha particle ripple loss in fusion reactors was first shown by Tani in simulations of the International Tokamak Reactor (INTOR) ${ }^{21}$. Although the importance of ripple 
losses was pointed out by Tani, White 22,23 and others over a decade ago, it is only with the development of recent advances in computation that detailed simulations of this type have become practical.

Putvinski 3 estimated such losses for ITER with 24 TF coils, concluding that alpha .ripple losses would not be a serious problem, being less than a few percent for $12 \mathrm{MA}$ and less than $0.63 \%$ at full current, 24 MA. The maximum wall load due to alpha.loss was estimated to be $1 \mathrm{MW} / \mathrm{m}^{2}$. The simulations presented here are for the $21 \mathrm{MA}, 20$ TF coil ITER design, and are based on comprehensive, selfconsistent TRANSP simulations 24 of two testbed ITER scenarios on which this and other theoretical and modelling studies have been focussed. The 24 TF coil design had maximum TF ripple $2.1 \%$, reduced to $1.8 \%$ for the 20 TF coil design 3 .

In the last few years, the ORBIT Hamiltonian coordinate 22 guiding center code 23 has been used extensively to quantitatively evaluate TF ripple losses for TFTR alpha particles 13,14 and to renormalize a simple model for stochastic ripple losses within the TRANSP code 12,25. It was found for TFTR that collisions are far more important than had been expected, with pitch angle scattering during the alpha particle slowing down time causing losses to be about twice those estimated without collisional effects. The effect of including both ripple and collisional physics in the simulations was seen to be highly nonlinear, with synergism $S$ defined as the loss with ripple and collisions divided by the sum of the losses obtained with ripple alone and with collisions alone. For TFTR it was found that $S \sim 2$ for both neutral beam ions and for alpha particles. A simple linear superposition of loss rates was found inadequate. A similar approach has been taken here for the 20 TF coil ITER design, with collisional effects included in detail.

ITER equilibria were obtained with the PEST code 26 using pressure and q profiles from TRANSP24, based on cases in the ITER database obtained from D. Boucher, ITER Joint Central Team (JCT), San Diego, CA. Two ITER scenarios were studied, one with moderately peaked density profiles (scenario I) and one with flat profiles (scenario II). Figure 1 shows the equilibrium for ITER scenario I and maximum TF ripple contours. TRANSP simula- 
tions of ITER also provided alpha source profiles, before and after sawtooth broadening, as well as collision rates for use in ORBIT.

\section{II.A ITER toroidal field ripple model}

The tokamak toroidal field (TF) ripple is defined as

$$
\delta=(B M A X-B M I N) /(B M A X+B M I N),
$$

where BMAX and BMIN are the maximum and minimum field magnitudes at constant major radius and elevation. The TF ripple data field (Fig. 2) provided by the ITER JCT design team was fit to a simple analytic function by minimizing $\chi^{2}$. (Recall that for a function fit to a set of data, $\chi^{2}$ is defined as $\chi^{2}=\sum\left(F_{i}-f_{i}\right)^{2} / f_{i}$, where $F_{i}$ and $f_{i}$ are the values of the function and the data respectively at the ith point.

Earlier work for TFTR27 was followed, choosing the analytic form for the TF ripple as

$$
\delta(R, Z)=\delta_{0} \exp \left\{\left[\left(R-R_{0}\right)^{2}+b_{r} Z^{2}\right]^{0.5} / w_{r}\right\}
$$

where $b_{r}$ is the ellipticity, $w_{r}$ is the scale length of the ripples, $\delta_{0}$ is the minimum value of the ripple field, and $R_{0}$ is the radius at which this minimum occurs for $Z=0$. The ripple field strength increases exponentially with the horizontal distance from the vacuum vessel center, $R$, and with vertical distance from the midplane, $Z$.

In contrast to TFTR, a plot of $\delta(R)$ for several values of $Z$ (Fig. 3) shows that $R_{0}$ depends on $Z$, being symmetric about $Z=0$ and essentially parabolic, $R_{0}=a+b Z^{2}$. The best approximation to these points was found to be $R_{0}=6.75-0.034 Z^{2} \cdot \chi^{2}$ was minimized for the function $\ln ^{2}(\delta(R, Z) / \delta 0)=\left[\left(R-R_{0}(Z)\right)^{2}+b_{r} Z^{2}\right] / w_{r}^{2}$. Values of $b_{r}$ and $w_{r}$ were obtained for the best linear combination of $\left[\left(R-R_{0}(Z)\right)^{2}+b_{r} Z^{2}\right] / w_{r}{ }^{2}$ corresponding to values of $\delta_{0}$. This procedure was carried out until the $\delta_{0}$ that produced a minimum for $\chi^{2}$ was found. The minimum value of $\chi^{2}, 0.00334$, occurs when $\delta_{0}=3.75 \times 10^{-}$ 6 , with $w_{r}$ and $b_{r}$ being $0.535 \mathrm{~m}$ and 0.268 , respectively. Comparisons between the data and the analytic fit at the midplane, $Z=0$, versus major radius and at $R=10.75 \mathrm{~m}$ versus height are shown in Fig. 4. 


\section{II.B Guiding center code simulation parameters}

Initially, Monte Carlo simulations with the PEST equilibrium and the analytic TF ripple field were carried out for 256 alpha particles of birth energy $3.5 \mathrm{MeV}$. Simulation parameters were major radius $8.14 \mathrm{~m}$, minor radius $2.8 \mathrm{~m}$, plasma current $21 \mathrm{MA}$, toroidal field $5.7 \mathrm{~T}$ at $R_{m}=8.48 \mathrm{~m}$ and edge $\mathrm{q}$ of 3.3. The alpha particle source profiles were calculated by TRANSP from simulation of DT fusion, with prescribed D and T profiles and a simple Kadomtsev sawtooth model 24 .

For scenario I two different alpha source profiles occur in the TRANSP simulations: a peaked, pre-sawtooth profile and a flat, sawtooth-broadened profile (Fig. 5). Particles are distributed primarily according to the pre-sawtooth profile, although periodically a sawtooth broadened profile of short duration is seen, due to the magnetohydrodynamic (MHD) sawtooth instability. The pre-sawtooth profile is modelled by the function $(1-|x|)^{3}$ with $x=r / a$, the normalized minor radius at the midplane, and the sawtooth broadened profile is modeled in two ways: (a) with a combination of two Heaviside functions $[H(x)-H(0.7-x)]$, and (b) with a trapezoid whose diagonal side extends from $0.5 \mathrm{r} / \mathrm{a}$ to $0.7 \mathrm{r} / \mathrm{a}$; no particles outside $\mathrm{r} / \mathrm{a}=0.7$ in either case. As results of simulations for both types of sawtooth broadened profile models were similar; only simulation results from the first sawtooth broadened profile model (a) are discussed.

The simulations included pitch angle scattering and collisional slowing down. Collision rates used were $v_{\text {perp }} \alpha=0.126 \mathrm{sec}^{-1}$ and $v_{\varepsilon}^{\alpha}=5.0 \mathrm{sec}^{-1}$, corresponding to radially constant energy diffusion and energy loss rates. The toroidal transit time for an alpha particle at the magnetic axis with pitch $\lambda=v / / / v=1$, was $3.92 \mu$ seconds. Typical simulations followed particles for 51,000 toroidal transit times

\section{RESULTS AND DISCUSSION}

\section{III.A. Simulations of scenarios I and II}

Guiding center code simulations of ITER scenario I with presawtooth alpha profile showed no losses of the 256 particles followed, for simulations including collisional pitch 
angle scattering over one alpha slowing down time. Monte Carlo errors in the particle loss calculations are approximated by $n 0.5 / n T$ where $n$ is the number of particles lost and $n T$ is the total number of Monte Carlo particles followed. When simulations yield no particles lost, the error will be less than calculated for one lost particle $(+/-0.4 \%)$, and an upper bound to alpha ripple losses is $\sim 0.4 \%$ in the new design.

Sawtooth broadening of the alpha profile in scenario I led to small alpha losses. Two particles of 256 were lost, corresponding to $0.8 \%+1-0.6 \%$ and power losses of $0.7 \%$. The physics of the sawtooth instability is an active area of present research with the details of the sawtooth magnetic field reconnection and its effect on the fast particle distribution function not yet known. Some general conclusions can be reached from present modelling as well as from observation of tokamak experimental data. Transport simulations of ITER 24,28 show that the alpha profile is sawtooth broadened for only a small fraction of the ITER pulse length. Because of the very short duration of sawtooth broadened alpha profiles in experiments and in present models of the sawtooth instability, the pulse averaged energy losses will be virtually unaffected by the existence of sawteeth and so described by the upper bound $0.4 \%$.

Simulations were also carried out for the alternate ITER equilibrium scenario II based on very flat profiles 26 . As for the first ITER scenario with peaked profiles, a PEST equilibrium was obtained and 256 alpha particles from the TRANSP sawtooth average alpha source profile were followed with collisions for one slowing down time. The profile for this scenario, for which $R_{m}=8.39 \mathrm{~m}$, was modelled with a trapezoidal profile flat to $\mathrm{r} / \mathrm{a}=0.4$, decreasing linearly to zero at $r / a=0.7$. The slowing down and pitch angle scattering times are similar to those for scenario $\mathrm{I}$, as are the alpha profiles outside $r / \mathrm{a}=0.3$. No losses were simulated for scenario II so that as for scenario I alpha particle energy losses are $<0.4 \%$.

ORBIT simulations were also carried out for alpha losses from the sawtooth broadened ITER scenario I, with reversed direction of toroidal field. Reversal of toroidal field reverses the direction of the ripple trapped grad B drift. Ripple trapping losses are expected to occur during the first 25 toroidal transits, about $100 \mu \mathrm{sec}$ with reversed direction of toroidal field corresponding to upward grad B drift. Four particles were lost by upward ripple drifts, 
with reversed grad B drift, corresponding to (0.8)1.6\% (power)particle losses. Engineering estimates of damage to the top of the vacuum vessel arising from ripple trapped alphas, not driven by toroidal Alfven eigenmodes (TAE), MHD or application of $r$, can assume such losses are not greater than $1 \%$ with reversed toroidal drift direction.

\section{III.B Renormalization of stochastic threshold}

Goldston, White and Boozer ${ }^{19}$ have derived a widely used criterion for the occurence of stochastic ripple loss. A threshold is defined as

$$
\delta_{S}=(\varepsilon /(N \pi q))^{1.5}\left(1 / \rho q^{\prime}\right)
$$

where $\varepsilon=$ inverse aspect ratio, $N=$ number of coils, $q$ is the plasma safety factor, $q^{\prime}=d q / d r$ and $p$ is the ion Larmor radius. Trapped ions whose turning point lies in a region where the TF ripple $\delta$ exceeds the threshold $\delta_{s}$ are subject to stochastic ripple diffusion. This formulation neglects the effects of toroidal precession, collisions, banana width and up/down asymmetry.

A simple Goldston White Boozer criterion model was recently installed in the TRANSP code ${ }^{12}$, which was compared to ORBIT simulations of TFTR leading to a renormalization of $\delta_{\mathrm{S}}{ }^{\text {TFTR }}=0.5 \delta \mathrm{GWB}$. This renormalization compensates for the GWB model's simplification of the physics, and is thought to be driven primarily by toroidal precession and the large alpha particle banana widths in TFTR.

To renormalize the stochastic ripple loss model for ITER, losses from ORBIT and TRANSP simulations of scenario I are compared in Fig. 6. ORBIT energy loss for 256 particles was $0+/-0.4 \%$. TRANSP model calculations led to $1.5+/-1 \%$ alpha energy ripple losses for $\delta_{S}=\delta$ GWB and to $2.5+/-1 \%$ losses with $\delta_{S}=0.5 \delta$ GWB. Error bars on the TRANSP results are due to Monte Carlo statistics of the 1000 alpha particles simulated. While a spline fit to the TRANSP data points intersects the maximum loss from the ORBIT simulations at threshold renormalization factor $\sim 4$, considering the large error bars, we can say only that $\delta_{S}$ ITER $\geq \delta$ GWB. The unrenormalized GWB threshold might have been expected for the small banana width of alpha particles in ITER, however it appears that the 
threshold criterion is higher even with the strong asymmetry of the ITER equilibrium and ripple field. White has recently developed an improved treatment of the stochastic loss criterion which includes precession and is generalized for up/down asymmetry 29 .

The earlier 24 TF coil ITER design had higher TF ripple ranging from $2.1 \%$ to $1.5 \%$ at the plasma boundary associated with alpha ripple losses of $0.63 \%$. Reducing $N$ increases the threshold $\delta$ GWB and for the same TF coils would also increase $\delta$. In the 20 TF coil ITER design, the TF ripple has been reduced to less than $1.8 \%$ everywhere within the plasma, so that alpha particle stochastic losses are less.

\section{III.C. Heat load estimate}

Janeschitz 4 discusses many aspects of the new 20 TF coil design, including the heat load for which the first wall is designed $\left(0.5 \mathrm{MW} / \mathrm{m}^{2}\right)$. The heavily armored toroidal belt limiter, to be used for startup and shutdown, which is designed for $5.0 \mathrm{MW} / \mathrm{m}^{2}$ is located more than 3 meters below the magnetic axis height. The belt limiter would not protect the vacuum vessel from ripple lost alphas just below the midplane.

We estimate the heat load for maximum alpha ripple losses of $0.4 \%$. With a poloidal extent of about 30 degrees, the footprint of the alpha ripple loss will be $2 \pi(11 \mathrm{~m})(3 \mathrm{~m}) \sim 100 \mathrm{~m}^{2}$. Recent beta limit considerations for ITER limit the fusion power excursions to $1.8 \mathrm{GW} 30$. We estimate the maximum alpha ripple loss heat load by $0.4 \%$ of the $1800 \mathrm{MW}$ fusion power, reduced by 5 for the alpha fraction, divided by the impact area $100 \mathrm{~m}^{2}$, giving $\sim 0.01 \mathrm{MW} / \mathrm{m}^{2}$.

The wall heat load may be increased by effects of MHD and TAE enhanced losses in addition to a toroidal wall heat load peaking factor. For the 24 TF coil ITER, the effects of MHD and TAE enhanced losses were estimated to increase alpha losses and wall heat load by a factor of two, while an effective peaking factor (see below) increased the alpha wall maximum heat load by another factor of ten ${ }^{3}$.

The toroidal peaking factor will be above 1 because of i) possible misalignment of tiles, even $2 \mathrm{~mm}$ may be significant 18,31 ; ii) radial movement of the field line itself due to TF 
ripple since the field line will bow out between the TF coils; and iii) the edges of the ports near the midplane, which would intercept alpha loss otherwise distributed over the port area. Clever first wall design can eliminate or protect against these effects, knowing how much and where alpha loss is expected.

For 24 TF coils, estimates of $0.63 \%$ and $2.14 \%$ alpha ripple loss were made for operation at $24 \mathrm{MA}$ and $12 \mathrm{MA}$ respectively ${ }^{3}$. If the low/high current loss ratio is scaled to $20 \mathrm{TF}$ coils, we would also expect about $2 \%$ alpha ripple loss at low current. The reverse shear, advanced performance ITER design corresponds to similarly low plasma current ${ }^{32}$ and will need careful first wall design when the effects of TAE, MHD and toroidal heat peaking factors are included.

\section{CONCLUSION}

Calculations of collisional stochastic ripple loss of alpha particles from the new 20 toroidal field coil ITER predict less than $0.4 \%$ alpha losses at $21 \mathrm{MA}$. This is close to the loss previously calculated for the 24 TF design at full current. Simulations included effects of sawtooth broadening, flattened $\mathrm{H}$-mode profiles and pitch angle scattering over the alpha slowing down time. Slightly higher ripple trapping losses $(2+/-1 \%)$ were found for reversed direction of the toroidal field. A good analytic fit was obtained to the ITER ripple data field over the plasma cross section. In contrast to simulations of alpha particles for TFTR, the Goldston, White, Boozer criterion for ripple loss with increased renormalization factor $\delta_{\mathcal{S}} / \delta G W B \geq 1$ gave results in agreement with guiding center simulations of ITER.

Potentially serious wall damage issues appear to be avoidable for the 20 TF coil ITER, if the first wall is carefully designed to allow for predicted levels of alpha ripple loss and wall heating and if MHD and TAE enhanced loss is suppressed. Results of these and additional simulations at low current must be integrated with details of the uncompleted engineering design especially incorporating increased heating due to misaligned tiles or port edges, to determine the first wall heat load. 


\section{Acknowledgment}

We are glad to thank J. Manickam, W. Nevins, S. Putvinski, S. Scott, M. C. Zarnstorff, Y. Zhao and S. J. Zweben for their interest and help in this work and also R. J. Goldston, K. McGuire and N. Sauthoff for their interest and encouragement. This work was supported by the U.S. Department of Energy Contract No. DE-AC02-76-CHO-3073. C. O. Miller was suppported by a DOE National Undergraduate Research Fellowship.

\section{References}

1. Y. Shimomura, Overview of the International Thermonuclear Experimental Reactor, Physics of Plasmas, 1 (1994) 1610-1616.

2. P.-H. Rebut, V. Chuyanov, M. Huguet, R. Parker, and Y. Shimomura, IAEA-CN-60/E-1-11 "The ITER EDA outline design", in Plasma Physics and Controlled Nuclear Fusion Research 1994 (Proc,. 15th Int,. Conf,. Seville, (1994), International Atomic Energy Agency (IAEA), Vienna ) in press 1995.

3. S. Putvinski, H. Berk, P. Barabaschi, D. Borba, B. Breizman, J. Candy, C. Z. Chang, B. Coppi, N. Doinikov, G. Y. Fu, R. J. Hastie, G. Huysmans, W. Kerner, S. V. Konovalov, S. Migliuolo, F. Porcelli, F. Romanelli, M. Rosenbluth, S. Sharapov, K. Tani, K. Tobita, B. Tubbing, J. Van Dam, R. White, Y. Wu, P. N. Yushmanov, L. Zakharov, F. Zonca and S. Zweben, "Alpha-particle physics for ITER", in Plasma Physics and Controlled Nuclear Fusion Research 1994 (Proc. 15th Int. Conf. Seville, 1994), IAEA-CN-60/E-P-4, IAEA, Vienna, in press (1995). ITER Outline Design Report, Jan. 10, 1994, ITER JCT, San Diego, CA (private communication, S. Putvinski).

4. G. Janeschitz, Plasma Physics and Controlled Fusion 37 (1995) A19-A35.

ITER Interim Design Report, July 12, 1995, ITER JCT, San Diego, CA (private communication, S. Putvinski).

5. R. J. Hawryluk, D. Mueller, J. Hosea, C. W. Barnes, M. Beer, M. G. Bell, R. Bell, H. Biglari, M. Bitter, R. Boivin, N. L. Bretz, R. Budny, C. E. Bush, L. Chen, C.Z. Cheng, S. C. Cowley, D. S. Darrow, P. C. Efthimion, R. J. Fonck, E. Fredrickson, H. P. Furth, G. Greene, B. Grek, L. R. Grisham, G. Hammett, W. Heidbrink, K. W. Hill, D. Hoffman, R. A. Hulse, H. Hsuan, A. Janos, 
D. L. Jassby, F. C. Jobes, D. W. Johnson, L. C. Johnson, J. Kamperschroer, J. Kesner, C. K. Phillips, S. J. Kilpatrick, H. Kugel, P. H. Lamarche, E. Lawson, B. Leblanc, D. Manos, D. K. Mansfield, E. S. Marmar, E. Mazzucato, M. Mauel, M. P. McCarthy, J. Machuzak, D. C. McCune, K. M. McGuire, S. S. Medley, D. R. Mikkelsen, D. Monticello, Y. Nagayama, G. A. Navratil, R. Nazikian, D. K. Owens, H. Park, W. Park, S. F. Paul, F. W. Perkins, S. Pitcher, D. A. Rasmussen, M. H. Redi, G. Renda, G. Rewoldt, D. Roberts, A. L. Roquemore, S. A. Sabbagh, G. Schilling, J. Schivell, G. L. Schmidt, S. D. Scott, J. Snipes, J. Stevens, B. C. Stratton, J. D. Strachan, W. Stodiek, E. Synakowski, W. M. Tang, G. Taylor, J. Terry,J. R. Timberlake, K. Tobita, H. H. Towner, M.Ulrickson, S. Von Goeler, R. Wieland, J. R. Wilson, K. L. Wong, P. Woskov, M. Yamada, K. M. Young, M. C. Zarnstorff, and S. J. Zweben, Fusion Technol. 21, 1324 (1992).

6. R. Hawryluk, H. Adler, P. Alling, C. Ancher, H. Anderson, J. L. Anderson, J. W. Anderson, V. Arunasalam, G. Ascione, D. Ashcroft, C. W. Barnes, G. Barnes, S.

Batha, G. Bateman, M. Beer, M. G. Bell, R. Bell, M. Bitter, W. Blanchard, N. L. Bretz, C. Brunkhorst, R. Budny, C. E. Bush, R. Camp, M. Caorlin, H. Carnevale, S. Cauffman, Z. Chang, C.Z. Cheng, J. Chrzanowski, J. Collins, G. Coward, M. Cropper, D. S. Darrow, R. Daugert, J. Delooper, W. Dorland, L. Dudek, H. Duong, R. Durst, P. C. Efthimion, D. Ernst, H. Evenson, N. J. Fisch, R. Fisher, R. J. Fonck, E. Fredd, E. Fredrickson, N. Fromm, G-Y. Fu, T. Fujita, H. P. Furth, V. Garzotto, C. Gentile, J. Gilbert, J. Gioia, N. Gorelenkov, B. Grek, L.R. Grisham, G. Hammett, G. R. Hanson, W. Heidbrink, H. W. Herrmann, K. W. Hill, J. Hosea, H. Hsuan, M. Hughes, R. Hulse, A. Janos, D. L. Jassby, F. C. Jobes, D. W. Johnson, L. C. Johnson, M. Kalish, J. Kamperschroer, J. Kesner, H. Kugel, G. Labik, N. T. Lam, P. H. Lamarche, E. Lawson, B. Leblanc, J. Levine, F. M. Levinton, D. Loesser, D. Long, M. J. Loughlin, J. Machuzak, R. Majeski, D. K. Mansfield, E. S. Marmar, R. Marsala, A. Martin, G. Martin, E. Mazzucato, M. Mauel, M. P. McCarthy, J. McChesney, B. McCormack, D. C. McCune, K. M. McGuire, G. Mckee, D. M. Meade, S. S. Medley, D. R. Mikkelsen, S. V. Mirnov, D. Mueller, M. Murakami, J. A. Murphy, A. Nagy, G. A. Navratil, R. Nazikian, R. Newman, M. Norris, T. O'connor, M. Oldaker, J. Ongena, M. Osakabe, D. K. Owens, H. Park, W. Park, P. Parks, S. F. Paul, G. 
Pearson, E. Perry, R. Persing, M. Petrov, C. K. Phillips, M. Phillips, S. Pitcher, R. Pysher, A.L. Qualls, S. Raftopoulos, S. Ramakrishnan, A. Ramsey, D. A. Rasmussen, M. H. Redi, G. Renda, G. Rewoldt, D. Roberts, J. Rogers, R. Rossmassler, A. L. Roquemore, E. Ruskov, S. A. Sabbagh, M. Sasao, G. Schilling, J. Schivell, G. L. Schmidt, R. Scillia, S. D. Scott, I. Semenov, T. Senko, S. Sesnic, R. Sissingh, C. H. Skinner, J. Snipes, J. R. Stencel, J. Stevens, T. Stevenson, B. C. Stratton, J. D. Strachan, W. Stodiek, J.Swanson, E. Synakowski, H. Takahashi, W. M. Tang, G. Taylor, J. Terry, M. E. Thompson, W. Tighe, J. R. Timberlake, K. Tobita, H. H. Towner, M. Tuszewski, A. Von Halle, C. Vannoy, M. Viola, S. Von Goeler, D. Voorhees, R.T. Walters, R. Wester, R. B. White, R. Wieland, J. B. Wilgen, M. D. Williams, J. R. Wilson, J. Winston, K. Wright, K. L. Wong, P. Woskov G. A. Wurden, M. Yamada, S. Yoshikawa, K. M. Young, M. C. Zarnstorff, V. Zavereev, and S. J. Zweben, Plasma Physics and Controlled Nuclear Fusion Research (Proc. 15th Int. Conf., Seville, 1994) (International Atomic Energy Agency, Vienna, 1995), IAEA-CN-60/A-2-11-5.

7. R. B. White and H. E. Mynick, Phys. Plas. 1 (1989) 280.

8. P. Parks, Nuclear Fusion 35 (1995) 1297.

9. R. B. White, E. Fredrickson, D. Darrow, M. Zarnstorff, R. Wilson, S. Zweben, K. Hill, Yang Chen, Guoyong Fu, Phys. Plas. 2 (1995) 2871.

10. S. Putvinski, B. J. D. Tubbing, L.-G. Erriksson and S. V. Konovalov, Nucl. Fusion 34 (1994)495.

11. R. B. White and A. H. Boozer, Phys. Plas 2 (1995) 2915.

12. M. H. Redi, R. V. Budny, D. S. Darrow, H. H. Duong, R. K. Fisher, A. C. Janos, J. M. McChesney, D. C. McCune, S. S. Medley, M. P. Petrov, J. F. Schivell, S. D. Scott, R. B. White, M. C. Zarnstorff and S. J. Zweben, Nuclear Fusion 3512 (1995)1509-1516.

13. M. H. Redi, R. V. Budny, D. S. Darrow, A. C. Janos, D. C. McCune, S. S. Medley, J. F. Schivell, S. D. Scott, R. B. White, M. C. Zarnstorff and S. J. Zweben, in Plasma Physics and Controlled Nuclear Fusion Research 1995 (Proc. 22nd E. P. S. Conf. Bourriemouth, 1995), Il105 (1995).

14. M. H. Redi, M. C. Zarnstorff, R. B. White, R. V. Budny, A. C. Janos, D. K. Owens, J. F. 
Schivell, S. D. Scott and S. J. Zweben, Nuclear Fusion 3510 (1995) 1191-1211.

15. M. P. Petrov, R. V. Budny, H. H. Duong, R. K. Fisher, N. N. Gorelenkov, J. M. McChesney, D. K. Mansfield, S. S. Medley, P. B. Parks, M. H. Redi, A. L. Roquemore, Nuclear Fusion 35 (1995) 1437.

16. S. J. Zweben, D. S. Darrow, H. W. Herrmann, S. H. Batha, R. V. Budny, C.-S. Chang, Z. Chang, E. D. Fredrickson, D. L. Jassby, L. C. Johnson, F. M. Levinton, H. E. Mynick, D. K. Owens, J. F. Schivell, S. D. Scott, M. H. Redi, J. D. Strachan, K. Tobita and K. M. Young, Nuclear Fusion 35 (1995) 1445.

17. R. K. Fisher, J. M. McChesney, P. B. Parks, H. H. Duong, S. S. Medley, A. L. Roquemore, D. K. Mansfield, R. V. Budny, M. P. Petrov and R. E. Olson, Phys. Rev. Lett. 75 (1995) 846. 18. K. Tobita, K. Tani, Y. Kusama, T. Nishitani, Y. Ikeda, Y. Neyatani, S. V. Konovalov, M. Kikuchi, Y. Koide, K. Hamamatsu, H. Takeuchi, T. Fujii, Nuclear Fusion 35, 12 (1995) 1585. 19. R. J. Goldston, R. B. White and A. H. Boozer, Phys. Rev. Lett. 47 (1981) 647. 20. P. W. Anderson Concepts in Solids:Lectures on the Theory ofSolids (Benjamin, New York, 1963).

21. K. Tani, T. Takizuka, M. Azumi and H. Kishimoto, Nuclear Fusion 23 (1983) 657-665. 22. R. B. White, Phys. Fluids 27 (1984) 2466.

23. R. B. White and M. S. Chance, Phys. Fluids 27 (1984) 2466.

24. R. V. Budny, D. C. McCune, M. H. Redi, J. Schivell and R. M. Weiland, "TRANSP Simulations of Alpha Parameters and Ash in ITER", submitted, Nuclear Fusion (1995).

25. R. V. Budny, M. G. Bell, A. C. Janos, D. L. Jassby, L. C. Johnson, D. Mansfield, D. C. McCune, M. H. Redi, J. F. Schivell, G. Taylor, T. B. Terpstra, M. C. Zarnstorff and S. J. Zweben, Nuclear Fusion 34 (1994) 1247.

26. R. C. Grimm, J. M. Green, J. L. Johnson, Computational Physics 16 (1976) 253.

27. R. L. Boivin, S. J. Zweben and R. B. White, Nucl. Fusion 33 (1993) 449.

28. M. H. Redi, S. A. Cohen, J. Mat. Nucl. 176 \& 177 (1990) 262-267.

29. R. B. White, R. J. Goldston, M. H. Redi, R. B. Budny, "Ripple Induced Trapped Particle Loss in Tokamaks", Physics of Plasmas, submitted for publication (1996). 
30. G. Janeschitz, ITER JCT, Garching (private communication, 1995).

31. K. Tobita, Y. Neyatani, Y. Kusama, H. Takeuchi, Rev. Sci. Instr. 66 (1995) 594.

32. W. Nevins, LLNL (private communication, 1996).

\section{List of Figures}

Fig. 1. ITER equilibrium for scenario I with TF ripple contours.

Fig. 2. ITER ripple data field.

Fig. 3. Minimum ripple radius Ro versus $R$.

Fig. 4. Ripple data and fit at a) $Z=0$ and b) $R=10.75 \mathrm{~m}$.

Fig. 5. Alpha particle source profiles generated by the TRANSP code, showing pre-sawtooth and sawtooth broadened profiles for scenario I.

Fig. 6 Alpha particle energy ripple loss calculated with GWB criterion model in TRANSP as a function of inverse renormalization factor $\left[\delta_{S} / \delta G W B\right]^{-1}$. The maximum loss from ORBIT guiding center simulations is shown.

\section{DISCLAIMER}

This report was prepared as an account of work sponsored by an agency of the United States Government. Neither the United States Government nor any agency thereof, nor any of their employees, makes any warranty, express or implied, or assumes any legal liability or responsibility for the accuracy, completeness, or usefulness of any information, apparatus, product, or process disclosed, or represents that its use would not infringe privately owned rights. Referprocess disclosed, or represents that its use would not infringe private or service by trade name, trademark, ence herein to any specific commercial product, process, or service by trade name, trademark, manufacturer, or otherwise does not necessarily constitute or imply its endorsement, recommendation, or favoring by the United States Government or any agency thereor. The views and opinions of authors expressed herein do n 


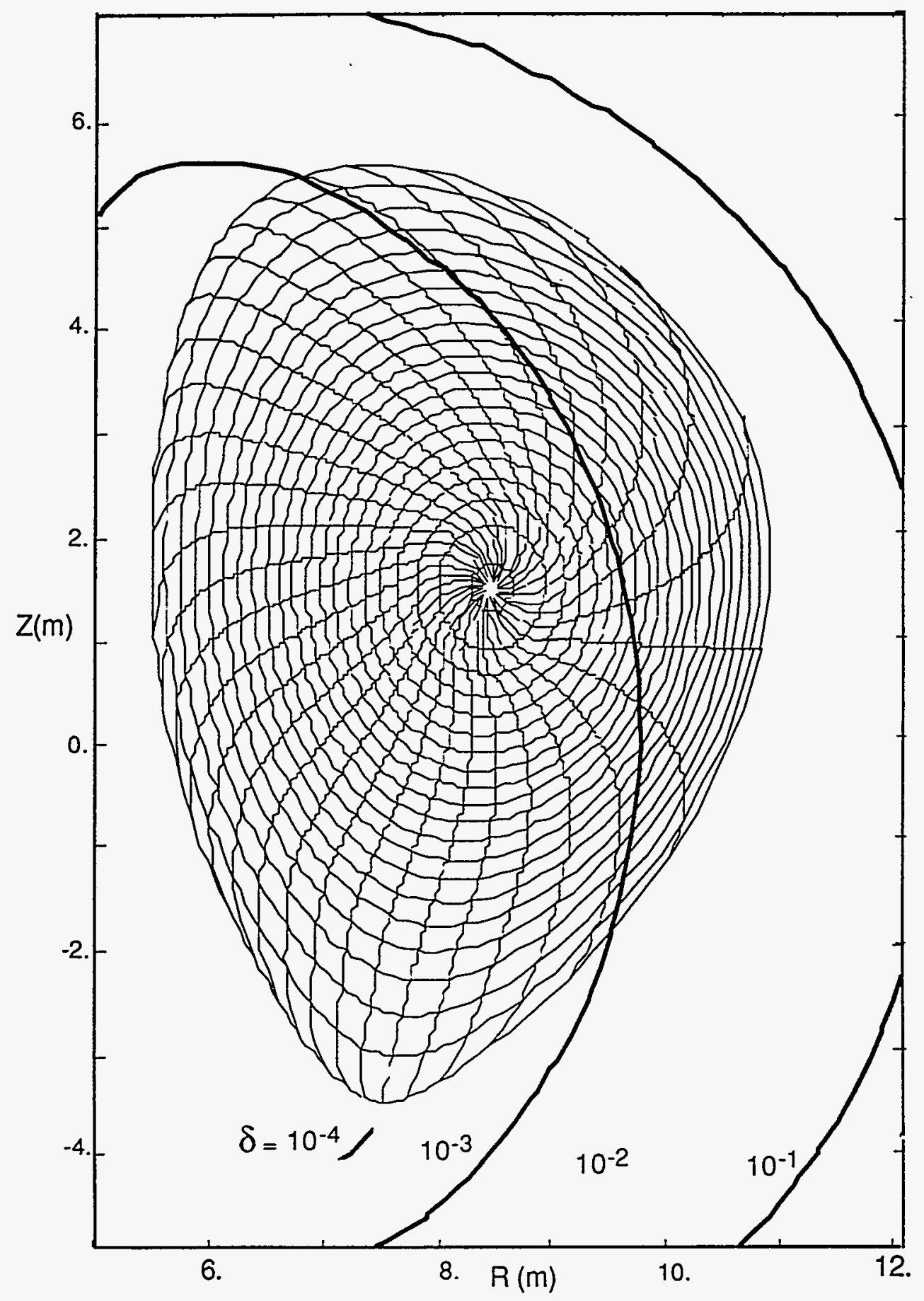

Figure 1 


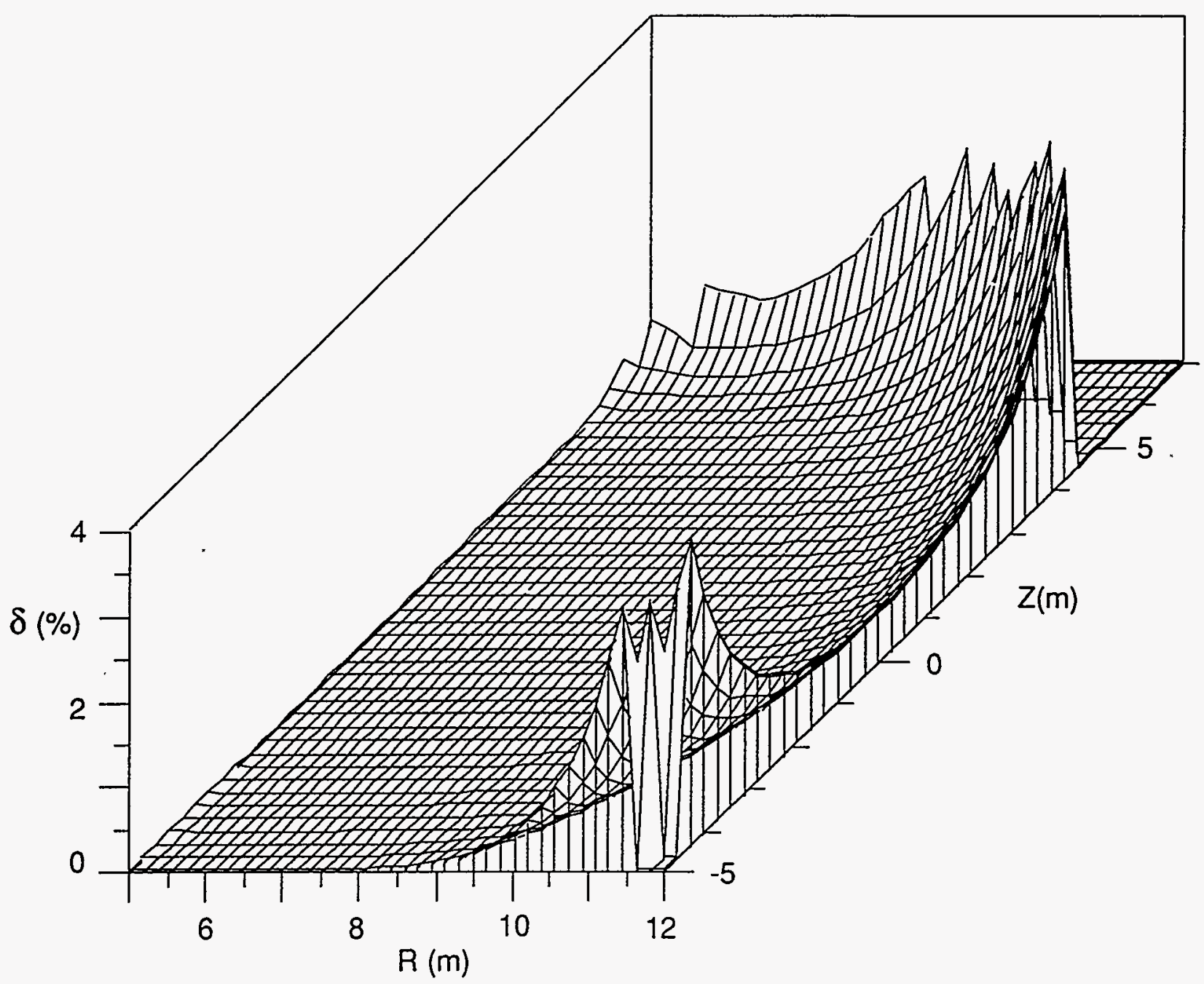

Figure 2 


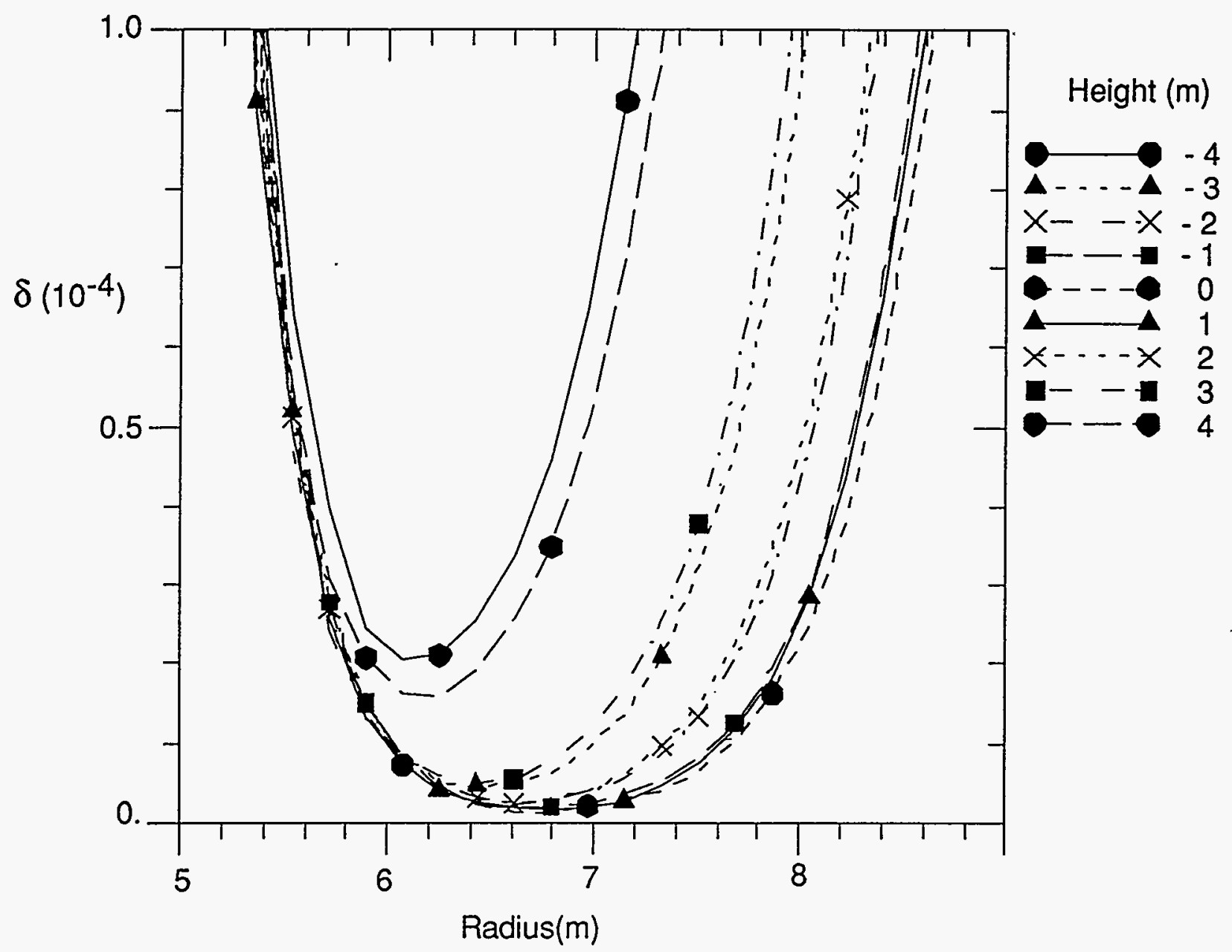

Figure 3 

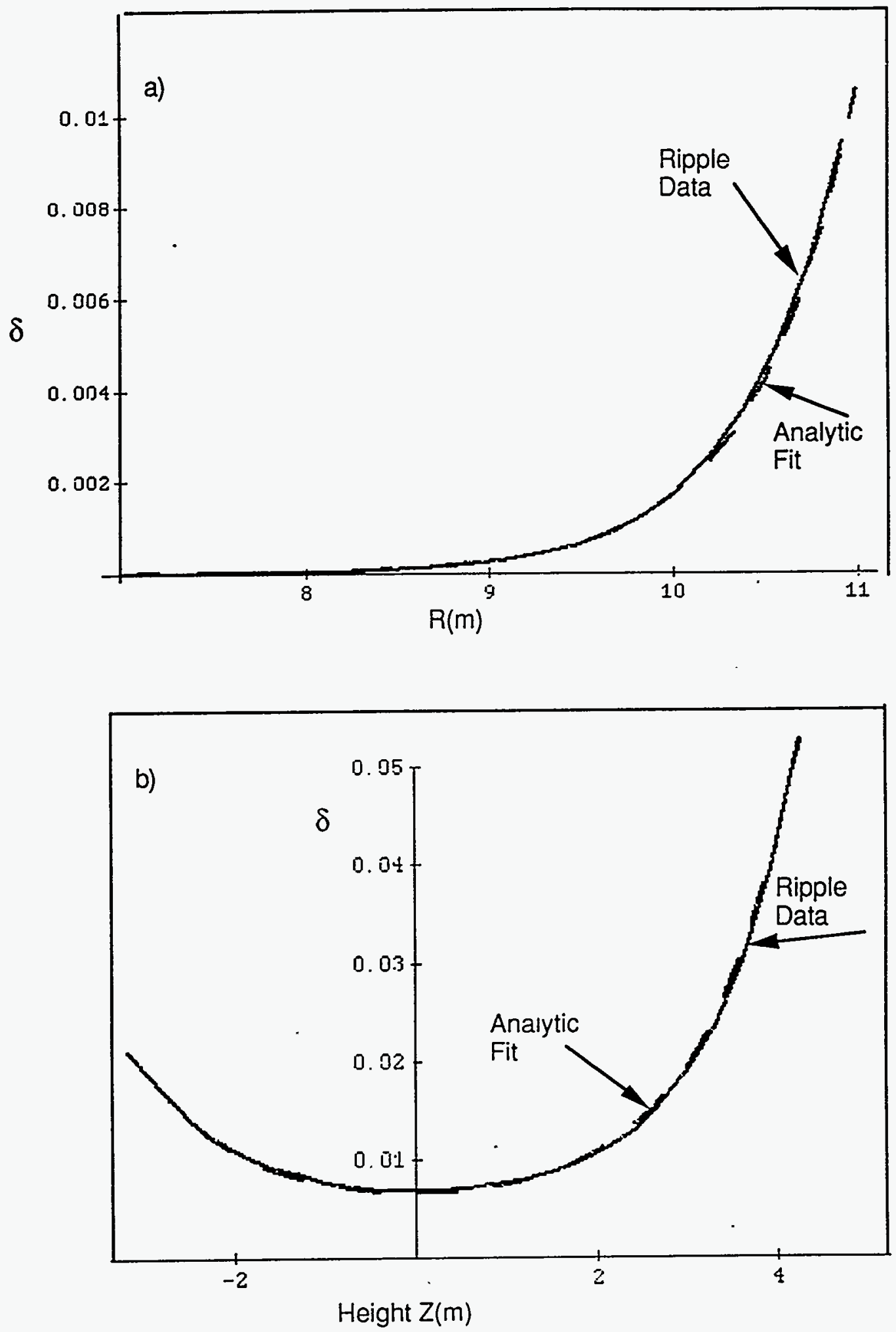

Figure 4 


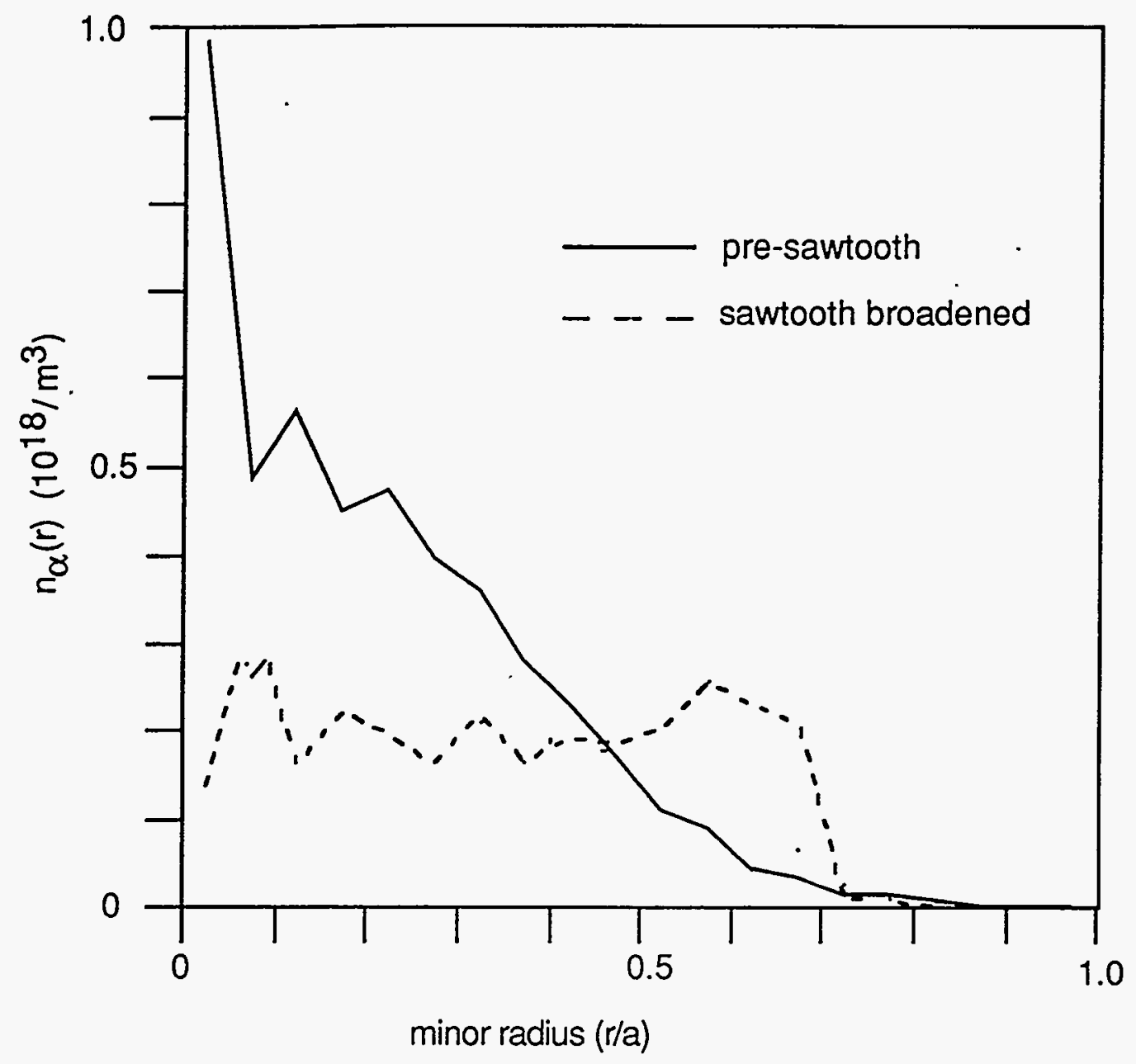

Figure 5 


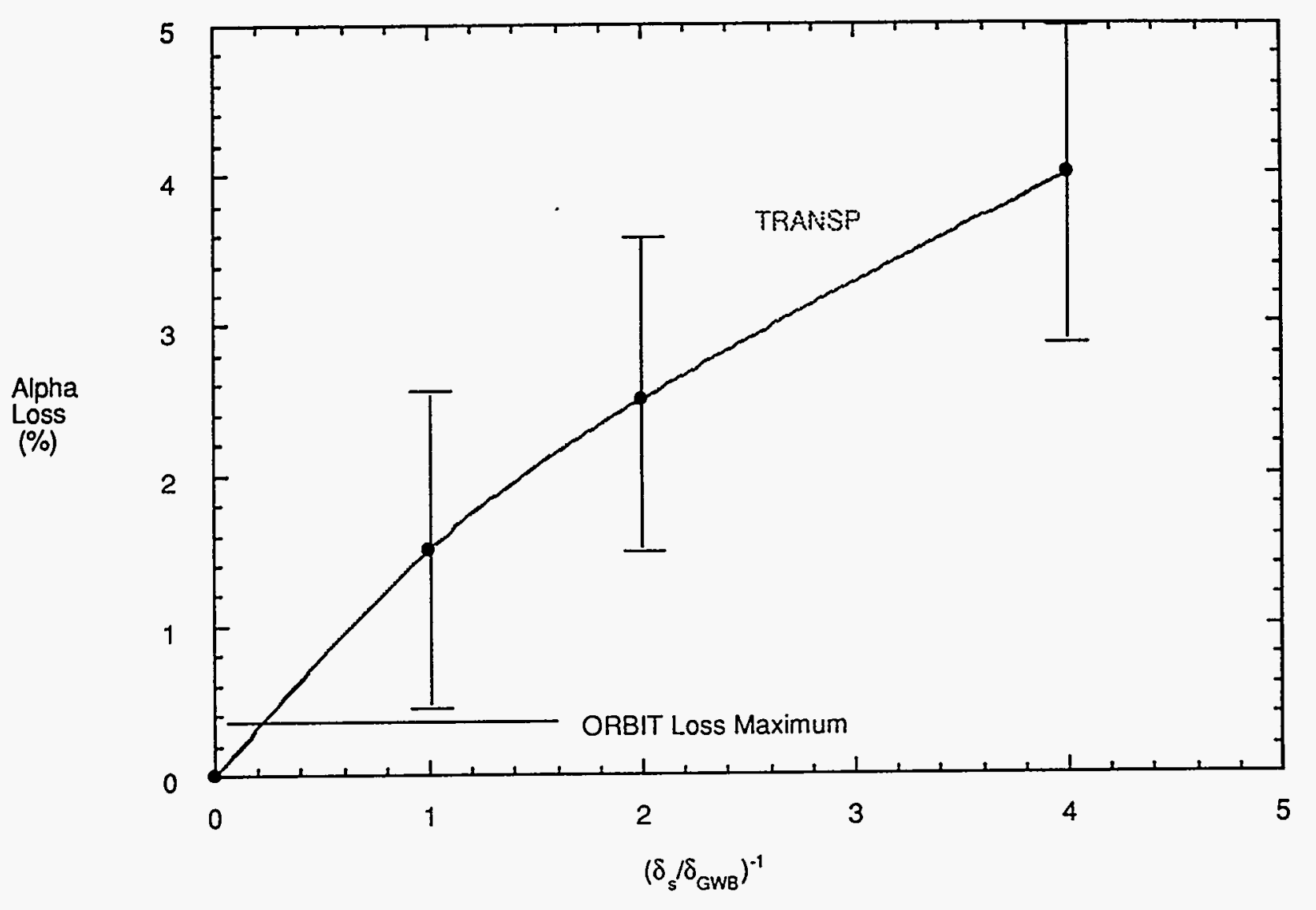

Figure 6 